\title{
Lugano Stage
}

National Cancer Institute

\section{Source}

National Cancer Institute. Lugano Stage. NCI Thesaurus. Code C141147.

An adult non-Hodgkin lymphoma and adult and childhood Hodgkin lymphoma stage

defined according to the Lug ano classification criteria. 